\title{
Quantification of the Components of Resistance to Rice Sheath Blight Using a Detached Tiller Test Under Controlled Conditions
}

Laetitia Willocquet, International Rice Research Institute (IRRI), Plant Breeding, Genetics and Biotechnology (PBGB) Division, DAPO Box 7777, Metro Manila, Philippines; Jagjeet S. Lore, Punjab Agricultural University, Ludhiana, 141004, India; and S. Srinivasachary and Serge Savary, IRRI, PBGB Division, Metro Manila, Philippines

\begin{abstract}
Willocquet, L., Lore, J. S., Srinivasachary, S., and Savary, S. 2011. Quantification of the components of resistance to rice sheath blight using a detached tiller test under controlled conditions. Plant Dis. 95:1507-1515.

Resistance of rice (Oryza sativa) to sheath blight, caused by Rhizoctonia solani, is quantitative and involves two mechanisms: physiological resistance and disease escape. The epidemiological concept of components of resistance was applied using a detached tiller method under controlled conditions, to specifically address physiological resistance to sheath blight in rice. A sclerotium was inserted below the leaf collar of individual rice tillers maintained in tubes filled with water. Different variables were measured after incubation: number of lesions, lesion length, vertical sheath colonization, presence or absence of dark margin at the edge of lesions, and survival duration of the leaf blade. Several rice

varieties reported to have different levels of susceptibility to sheath blight were assessed, together with varieties that are cultivated over large areas. Although numerical differences between rice varieties were observed for all disease variables, only the number of lesions significantly differed among varieties tested in this study. The varieties Pecos and IR64 had the consistently lowest and highest disease intensities, respectively. This methodology may allow the detection of sources of resistance that specifically involve defense mechanisms. When combined with field assessment, this methodology should also enable to quantitatively assess the relative role of both mechanisms of resistance to sheath blight.
\end{abstract}

Rice sheath blight, caused by Rhizoctonia solani, occurs in all areas where rice (Oryza sativa) is grown (18), and is particularly important when rice is grown intensively (34). The average yield losses caused by sheath blight in the lowland rice of tropical Asia range from 5 to $10 \%(33,48)$. The fungus has a very wide host range and can infect more than 32 plant families and 188 genera (41). The pathogen does not produce spores, and lesion multiplication in a rice canopy occurs through the growth of runner hyphae from a (mother) lesion at the surface of rice tissues (leaf sheath of blade), which establishes penetration structures to produce a new (daughter) lesion (18). Disease spread between tillers therefore requires a physical contact between an infectious and a healthy tiller, and increased contact frequency between tillers enhances disease extensification (32). The duration of canopy wetness is another key factor favoring both disease intensification (within a tiller) and extensification between tillers or plants (32).

Host plant resistance represents a key approach for disease management, because it is a pro-poor, environment-friendly technology that can efficiently suppress disease epidemics. In the case of sheath blight, only quantitative (partial) resistance can be expected in rice, given the biology and wide host range of the pathogen $(23,41)$. Screening for host plant resistance to rice sheath blight has been conducted for many years in different research centers, including IRRI, where more than 30,000 accessions have been tested (17). Over the past decade, screening in rice germplasm and in rice

\section{Corresponding author: L. Willocquet, E-mail: L.Willocquet@cgiar.org}

* The $\boldsymbol{e}$-Xtra logo stands for "electronic extra" and indicates that Figures 2 through 5 appear in color in the online edition.

Accepted for publication 9 June 2011.

doi:10.1094/PDIS-01-11-0051

(C) 2011 The American Phytopathological Society wild species, as well as mapping of quantitative trait loci (QTL) associated with disease resistance, have been conducted, using an array of approaches $(5,23,25)$. In spite of these efforts, no rice variety with a high level of resistance is currently deployed in Asia (41).

The quantitative measurement of the effect of partial resistance on the different stages of the disease cycle and the prediction of these effects on plant disease epidemics can be achieved using the concept of components of resistance $(20,22,50)$. Quantitative resistance can be divided into components, each affecting a different stage of the pathogen-host interaction: resistance to infection, colonization, and reproduction. These components of resistance can be quantified in the case of aerial, spore-producing fungi by measuring infection frequency, latent period, spore production, and colony size for a set of plant genotypes, including a susceptible control, and by computing for each component relative resistance terms, whose values depend on measurements taken in comparison to a susceptible control $(20,50)$. The measurement of components of resistance, expressed as relative resistance terms, allows identifying factors that will induce the strongest epidemic reduction. These components of resistance, in turn, can become targets to include in breeding programs, and can be identified through experimental (35) or modeling approaches $(14,45)$. Components of resistance have been measured for many plant diseases, for example in barley leaf rust (21), oat crown rust (6), barley yellow rust (29), Fusarium head blight of wheat (4), and tall fescue blast (44). Components of resistance have not been measured for rice sheath blight, but components related to lesion size have been quantified for another disease caused by $R$. solani, Rhizoctonia blight of tall fescue (8). Resistance can furthermore be assessed by describing reaction types (51), which may in some cases reflect both quantitative and qualitative (e.g., chlorotic tissue) effects of host plant resistance (20).

Resistance to sheath blight is associated with quantitative, complex traits $(23,41)$, and it can be hypothesized to include two main groups of mechanisms: physiological resistance and disease escape (41). Disease escape or avoidance (20) corresponds to mechanisms 
by which structural or morphological features of the plant hamper processes involved in the disease cycle, and can represent an important component of resistance (24). In the case of rice sheath blight, morphological traits resulting in a rice canopy with reduced contact frequency between tissues and reduced duration of canopy wetness may lead to disease escape $(26,27)$. Physiological resistance, in turn, corresponds to processes of the plant, constitutive or induced, that are associated with a decrease in efficiency of one or several of the infection or reproductive stages of the pathogen $(24,28,41)$.

The confounding between physiological resistance and disease escape mechanisms in earlier screening or phenotyping studies may be connected to the identification of QTL associated with resistance to sheath blight which are co-localized with QTL for plant height or crop cycle duration $(23,38,41)$. This may partly explain the slow progress achieved to improve rice varieties with respect to resistance to sheath blight (41). The quantification of the respective roles of physiological resistance and disease escape on the overall resistance to sheath blight may thus allow further progress in identifying sources of resistance, and in establishing breeding programs to improve resistance to sheath blight. A detailed and quantitative measurement of the components of physiological resistance on one hand, and of disease escape on the other hand, based on epidemiological concepts, may thus provide a relevant basis to quantify both mechanisms of resistance and their respective importance, and to identify potential donors for both groups of traits. In this article, we attempt to address the first group of resistance mechanisms by describing a detached tiller test method to derive the components of physiological resistance to rice sheath blight.

\section{Materials and Methods}

In order to derive the components of physiological resistance to rice sheath blight, the detached tiller test was developed to minimize the effect of disease escape: tests were (i) conducted under controlled conditions, where the microclimate (and especially leaf wetness) is standardized, and (ii) conducted on only one organ (one tiller), thus negating disease spread among tillers through plant tissue contacts, which is the primary mechanism to explain disease escape at the canopy scale.

Plant material. Fifteen rice varieties with different levels of reported susceptibility and Asian "mega-varieties" (i.e., grown over large areas) were used (Table 1). The material consisted of tillers detached from the selected rice varieties grown in a screenhouse, so that roots remained attached to the tillers. Tiller collection was made 36 to 38 days after transplanting of 14-day-old seedlings. The roots were washed under tap water, and each tiller was placed in a test tube filled with $10 \mathrm{ml}$ of distilled water (Fig. 1A).

Table 1. Varieties used in the detached tiller tests to measure resistance components in rice sheath blight, caused by Rhizoctonia solani

\begin{tabular}{ll}
\hline Basis of selection of varieties & Variety name $^{\mathbf{a}}$ \\
\hline Varieties with reported resistance & Teqing $(15,19,23)$ \\
to sheath blight & Tetep $(5,30,37,46)$ \\
& Pecos $(3,38)$ \\
& Padi-pulut-malat (39) \\
& Dudruchi (39) \\
& Kakua (39) \\
& Khakibinni (39) \\
& Betichikon (39) \\
& Khato-chalani (39) \\
& PSBrc52 (43) \\
Variety reported with moderate & \\
susceptibility to sheath blight & IR58 (1,10,11,39) \\
Varieties reported highly susceptible & Swarna ${ }^{\text {b }(42)}$ \\
to sheath blight & IR64 (13) \\
Varieties grown in large areas & IR72 (13) \\
& PSBrc18 (13) \\
\hline
\end{tabular}

${ }^{a}$ References are provided in parentheses.

b Swarna is also a mega-variety in South Asia.
Inoculation method, disease assessment, and experimental design. The inoculum consisted of 7-day-old sclerotia (Fig. 1B) obtained by placing at the center of each $9.5-\mathrm{cm}$-diameter petri dish filled with potato dextrose agar (PDA [extract from $200 \mathrm{~g}$ of potato, $20 \mathrm{~g}$ of dextrose, and $20 \mathrm{~g}$ of agar per liter]) a sclerotium produced in the same way, and incubating at $28^{\circ} \mathrm{C}$ in darkness. The isolate LR-1, isolated in 1986 at the IRRI experimental farm, was used to prepare the inoculum. This isolate, when inoculated on rice, produces typical sheath blight symptoms on sheath and leaves. Mycelial growth and sclerotia production are also typical of $R$. solani. To standardize the inoculum, only sclerotia with a diameter size of $1.5 \pm 0.3 \mathrm{~mm}$ were used.

Tillers were inoculated by transferring a single sclerotium just below the leaf collar, on the inner side of the sheath, of the second top-most collar of the tiller, thus corresponding to the second or third leaf of the tiller from the top (Fig. 1C). Similar inoculation methods have been used for epidemiological, screening, or phenotyping studies on rice sheath blight $(5,40)$, but not on detached tillers.

The inoculated tillers were grouped in tube racks. Each group of tillers was sprayed with distilled water and placed into a transparent plastic bag to provide an environment where air was saturated with humidity and tissue surface was moist. The racks were transferred into a growth chamber at $25^{\circ} \mathrm{C}$, with a 12 -h photoperiod, and light intensity of $30 \mu \mathrm{E} \mathrm{s}^{-1} \mathrm{~m}^{-2}$ until disease assessment (Fig. 1D).

Disease assessment was performed 5, 7, and 10 days after inoculation (DAI). The following disease variables were measured for each tiller: number of lesions; length of each lesion; distance between the inoculum and the tip of the furthest lesion; and distance between the tips of the lowest and highest lesions on the sheaths (vertical sheath colonization [VSC]). The distance from the base of the tiller to the collar of the topmost leaf (sheaths length) was also measured. The relative vertical sheath colonization (RVSC) was computed as $100 \times \mathrm{VSC} /$ sheaths length. The occurrence of a black margin on lesions, and the status (alive or dead) of the leaf blade just next to the inoculation site were also recorded.

Five independent experiments were performed. Each experiment was arranged according to a randomized complete block design, with three blocks including each of the 15 rice varieties assigned at random. For each assessed tiller, the measurements of lesion length made on all lesions were used to derive the maximum lesion length and the mean lesion length. RVSC values were arcsine transformed before analyses of variance. The proportion of dead leaf blades was computed for each variety using combined data from the five experiments.

Data analyses. An overview of the data structure and of the relationships between the different disease variables measured was first obtained by computing Pearson correlation coefficients for pairwise variables and their associated probabilities. Second, a principal component analysis was performed using the number of lesions, maximum lesion length, mean lesion length, distance between the inoculum and the furthest lesion, VSC, and RVSC, to describe the relationships among these six variables. This analysis was performed using SYSTAT 12 (SYSTAT Software).

In a second stage of analysis, data from all five experiments were used to perform repeated measures analyses of variance to test the effects of rice varieties on the different disease variables using the MIXED procedure of SAS (SAS Institute). For each variable analyzed, the rice variety was considered a fixed effect, while the assessment day was considered a fixed, repeated effect, and replication (block) within each experiment was considered a random effect. The experiments were considered fixed effects, so that the experiment $\times$ variety interaction could be tested. In each analysis, the compound symmetry (CS; with a constant variance and a constant covariance) structure of the variance-covariance matrix of residuals was considered $(16,36)$. For each variable analyzed, LSD was calculated as $2 \times$ MAX (SED), where SED is the standard error of difference of least squares means.

In a third stage of analysis, mixed model analyses of variance were performed for each variable and for each assessment date, in order to compare the different assessment dates with respect to the detection of effect of varieties on the different disease variables. 
The MIXED procedure of SAS was used, considering rice variety and experiment as fixed effects, and replications (blocks) within experiments as random effects.

Lastly, a hierarchical cluster analysis was conducted in order to group the varieties according to disease variables measured. The means of the disease variables at 7 DAI for each rice variety over the five experiments were used to perform the cluster analysis, using the Ward criterion and a Mahalanobis distance, which is scale-invariant $(7,47)$.

\section{Results}

Relationships between disease variables measured. The different variables measured were in general significantly $(P<$ 0.0001 ) correlated (Table 2), with correlation coefficients above 0.8 for the variable pairs (distance to furthest lesion and VSC) and (mean and maximum lesion length). The number of lesions per tiller and mean lesion length were less strongly correlated, compared to the other paired variables, with nonsignificant correlations at 7 and 10 DAI.

The principal component analysis generated two first axes, which captured the majority of the variance, as the first and second axes explained 75.6 and $14.5 \%$ of the variance, respectively (Fig. 2). All six disease variables were linked with the first axis, which was in agreement with the high coefficients of correlation found among these variables. On the second axis, however, (maximum and mean) lesion length had a negative coordinate, whereas the other variables had positive ones. Mean lesion length and number of lesions were the two most separated variables on this second axis. On this second axis, the variables RVSC, VSC, and distance to furthest lesion formed a cluster, which was more closely linked to the number of lesions than to lesion length variables.

Effect of varieties on sheath blight variables. Variety had the largest effect on the number of lesions $(F=2.44, P=0.004$; Table 3 ) and was not found to significantly affect the other disease variables. Experiments had a strong, significant $(P<0.0001)$ effect on all variables. Importantly, however, the interaction of variety $\times$ experiment was not significant, and was associated with $P$ values larger than 0.28 for all variables except mean and maximum lesion length, for which $P$ values were 0.06 and 0.001 , respectively. The assessment day $(5,7$, or $10 \mathrm{DAI})$ was the factor that had the largest effect on disease variables, with $F$ values larger than 32 . The interaction of variety $\times$ DAI was never significant, whereas the experiment $\times$ DAI interaction was always significant $(P<0.05)$.
Figure 3A shows the ranking of varieties (and the corresponding LSD) according to increasing number of lesions per tiller. The same ranking of varieties was used to display the other disease variables (Fig. 3B to F). The number of lesions per tiller ranged between 6.2 and 9.3. Pecos and Betichikon had the lowest and highest number of lesions per tiller, respectively. IR58 had the next lowest number of lesions (6.7). The number of lesions progressively increased from 7.4 to 9.3 among the 12 other varieties. IR64 and Swarna had more than 9 lesions per tiller, together with Betichikon. RVSC ranged from $27.9 \%$ (Pecos) to 39.6\% (Swarna; Fig. 3B). The varieties Padi-pulut-malat, PSBrc52, Kakua, Tetep, Khakibinni, Dudruchi, and Betichikon formed one group with a RVSC lower than $33 \%$. The ranking of varieties was in general similar with respect to mean and maximum lesion length (Fig. 3C and D). Lesion length was lowest for Swarna, Pecos, and PSBrc52, and highest for Dudruchi. VSC and distance to furthest lesion were highest for IR64 (Fig. 3E and F). Pecos, IR58, PSBrc52, and Swarna showed the lowest values for both variables.

When considering the different disease variables measured (Fig. 3), Pecos consistently had the first-to-fourth lowest values. IR58 was among the varieties with lowest number of lesions, VSC, and distance to furthest lesion, but had intermediate values for RVSC and lesion length. PSBrc52 was among varieties with lowest lesion length, VSC, and distance to furthest lesion, but had intermediate values for number of lesions and RVSC. Swarna was among the most susceptible varieties in terms of number of lesions and RVSC, but was among the less susceptible varieties in terms of lesion length, VSC, and distance to furthest lesion. IR64 had high values of number of lesions, RVSC, VSC, and distance to furthest lesion, and medium-high levels of lesion length. Khato-chalani and Dudruchi had among the largest values for all components, except RVSC. Betichikon had the highest number of lesions, and had among the highest distance to furthest lesion, but was associated with low levels of RVSC and lesion length.

Results from ANOVAs conducted for each assessment day indicated that variety significantly $(P<0.05)$ affected the number of lesions at all assessment dates, and RVSC at 5 DAI (Table 4). Variety effect on mean lesion length corresponded to a $P$ value of 0.05 at $5 \mathrm{DAI}$, and was not significant at other dates. Maximum lesion length, VSC, and distance to further lesion were not significantly affected by varieties.

Variety groups according to the components of resistance. Cluster analysis was conducted with three variables: number of

Table 2. Pearson correlation coefficients between the different rice sheath blight disease variables measured at 5 , 7 , and 10 days after inoculation on detached tillers

\begin{tabular}{|c|c|c|c|c|c|}
\hline & $\begin{array}{c}\text { Distance to furthest } \\
\text { lesion }\end{array}$ & $\begin{array}{l}\text { Sheath vertical } \\
\text { colonization }\end{array}$ & $\begin{array}{c}\text { Mean lesion } \\
\text { length }\end{array}$ & $\begin{array}{c}\text { Maximum lesion } \\
\text { length }\end{array}$ & $\begin{array}{c}\text { Relative sheath } \\
\text { vertical colonization }\end{array}$ \\
\hline \multicolumn{6}{|l|}{$5 \mathrm{DAI}^{\mathrm{a}}$} \\
\hline Number of lesions & 0.88 & 0.88 & 0.55 & 0.56 & 0.75 \\
\hline Distance to furthest lesion & & 0.94 & 0.66 & 0.66 & 0.85 \\
\hline Vertical sheath colonization & & & 0.71 & 0.71 & 0.89 \\
\hline Mean lesion length & & & & 0.92 & 0.65 \\
\hline Maximum lesion length & & & & & 0.71 \\
\hline \multicolumn{6}{|l|}{$5 \mathrm{DAI}^{\mathrm{b}}$} \\
\hline Number of lesions & 0.59 & 0.62 & 0.15 & 0.39 & 0.43 \\
\hline Distance to furthest lesion & & 0.89 & 0.61 & 0.70 & 0.69 \\
\hline Vertical sheath colonization & & & 0.65 & 0.72 & 0.77 \\
\hline Mean lesion length & & & & 0.83 & 0.48 \\
\hline Maximum lesion length & & & & & 0.58 \\
\hline \multicolumn{6}{|l|}{$10 \mathrm{DAI}^{\mathrm{c}}$} \\
\hline Number of lesions & 0.52 & 0.61 & -0.04 & 0.27 & 0.59 \\
\hline Distance to furthest lesion & & 0.92 & 0.54 & 0.63 & 0.70 \\
\hline Vertical sheath colonization & & & 0.55 & 0.64 & 0.76 \\
\hline Mean lesion length & & & & 0.83 & 0.30 \\
\hline Maximum lesion length & & & & & 0.47 \\
\hline
\end{tabular}

a All associated $P$ values were $<0.0001$ at 5 days after inoculation.

${ }^{\mathrm{b}}$ All associated $P$ values were $<0.0001$ except for number of lesions and mean lesion length $(P=0.21)$ at 7 days after inoculation.

${ }^{\mathrm{c}}$ All associated $P$ values were $<0.0001$ except for number of lesions and mean lesion length $(P=0.73)$, and number of lesions and maximum lesion length $(P=0.02)$ at 10 days after inoculation. 
lesions, maximum lesion length, and VSC. Mean lesion length and distance to furthest lesion were omitted, because they were highly correlated to maximum lesion length and VSC, respectively. RVSC was not included because this variable may partly reflect disease escape mechanisms. Thus, the three variables selected captured the main components of resistance measured with respect to physiological resistance. Three main groups were identified from the hierarchical cluster analyses: a first group with Pecos and PSBrc52, a second with Swarna, Tetep, Khakibinni, and Betichikon, and the third, larger group including all the other varieties (Fig. 4). The first group corresponded to lowest average values in number of lesions (7.2), VSC $(82 \mathrm{~mm})$, and maximum lesion length $(23.2 \mathrm{~mm})$. The second group had the highest average number of lesions, and intermediate values for VSC and maximum lesion length.
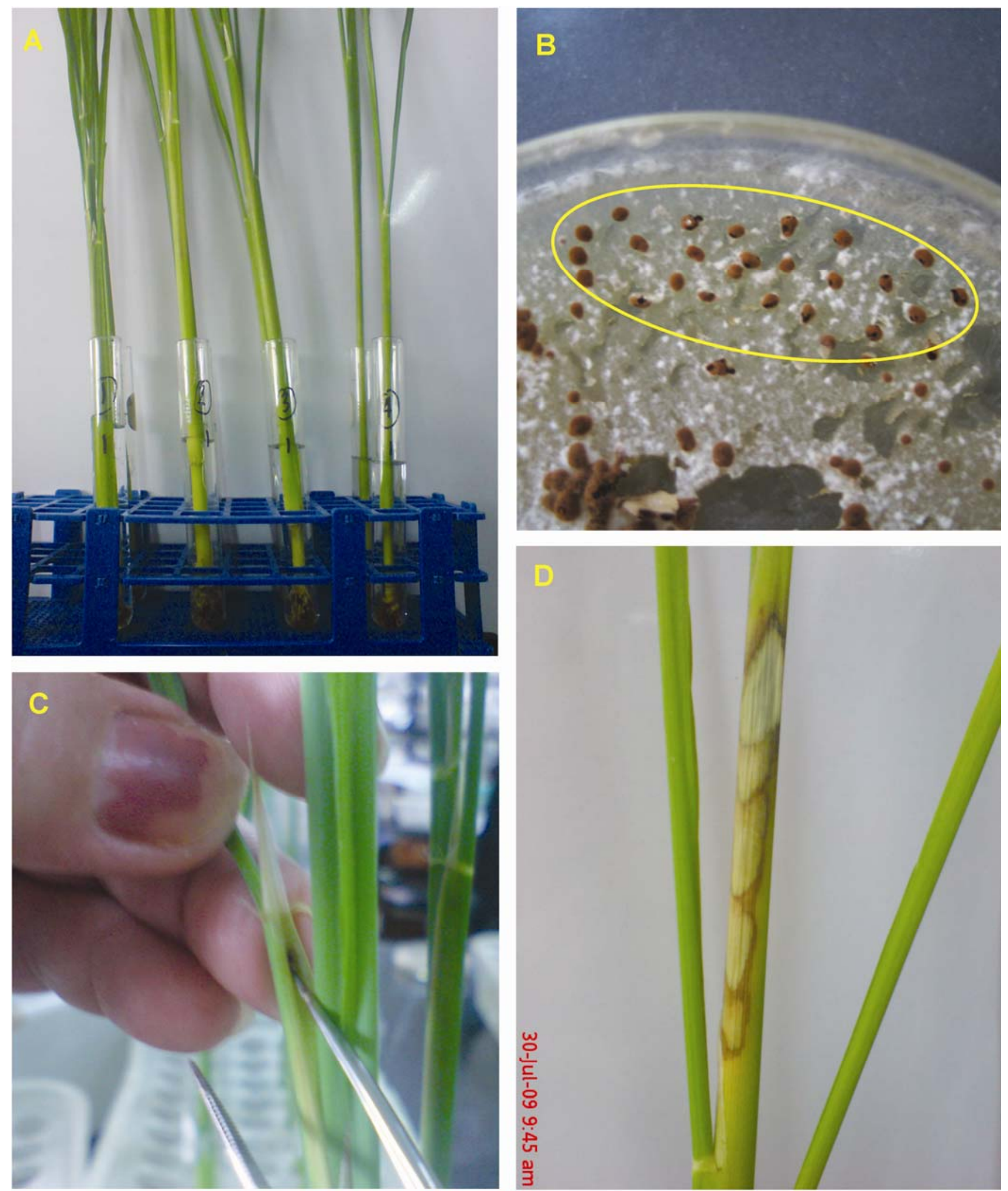

Fig. 1. Different steps of the detached tiller method to measure resistance components in rice sheath blight, caused by Rhizoctonia solani: A, detached tillers placed in test tubes filled with distilled water; B, inoculum: 7-day-old sclerotia; C, inoculation: insertion of a sclerotia below the leaf collar; D, lesions observed 7 days after inoculation. 


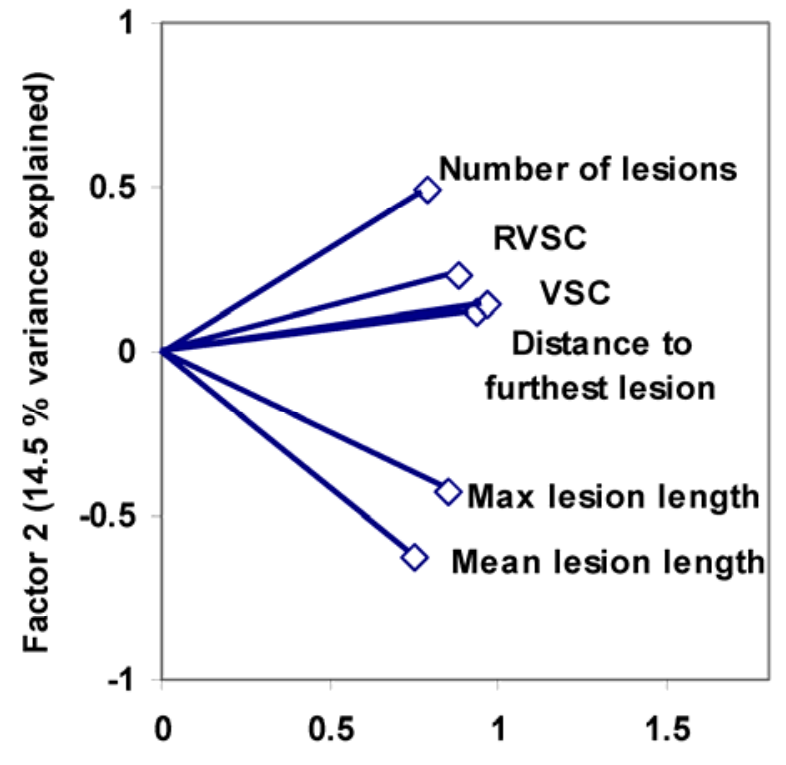

Factor 1 (75.6\% variance explained)

Fig. 2. Principal component analysis from rice sheath blight disease variables measured after inoculation on detached tillers. VSC: Vertical sheath colonization; RVSC: relative vertical sheath colonization. Results are from five independent experiments with 15 rice varieties.
Effect of variety on leaf blade senescence and occurrence of dark margin. Proportion of dead leaves at 7 DAI ranged from 0.20 (Teqing) to 0.80 (Khakibinni; Fig. 5). The next lowest values were observed for Tetep (0.36) and Betichikon (0.40). The highest proportion of dead leaves was observed for IR64 (0.73) and PSBrc18 (0.71). Occurrence of a dark margin was observed in only one instance each in varieties Betichikon and Khakibinni.

\section{Discussion}

The concept of components of resistance was adapted to the particular epidemiological features of sheath blight, which especially include the fact that the fungus does not produce asexual spores (18). Incubation period was not measured, because it was, in our conditions, very short (3 days), thus not allowing high precision, and because of the difficulty in determining when a lesion was established (as symptoms progressively evolved from water-soaked to well-delineated lesions). The measurement of latent or infectious period was not attempted here, again because the fungus does not produce spores in its vegetative spread phase.

A range of complementary variables were used to describe the disease cycle. The number of lesions was used to quantify the infection efficiency of the pathogen, i.e., its capacity to infect the host tissue and produce lesions. This variable was the most discriminating and showed consistent results, as no significant experiment $\times$ variety interaction was detected. No significant effect of variety on lesion length (maximum and average) was detected from our experiments. Lesion length, however, represents another key component of resistance, reflecting the capacity of the pathogen to progress and the lesion to expand. It should therefore be measured when comparing rice varieties, because differences may be de-

Table 3. Repeated measures analyses of variance on the effects of variety, day after inoculation, and experiment on rice sheath blight disease variables after inoculation on detached tillers

\begin{tabular}{|c|c|c|c|c|c|}
\hline Variable analyzed & Effect $^{\mathrm{a}}$ & Num df & Den df & $F$ value & $P>F$ \\
\hline Number of lesions & $\begin{array}{l}\text { Var } \\
\text { Experiment } \\
\text { DAI } \\
\text { Var } \times \text { experiment } \\
\text { Var } \times \text { DAI } \\
\text { Experiment } \times \text { DAI }\end{array}$ & $\begin{array}{r}14 \\
4 \\
2 \\
56 \\
28 \\
8\end{array}$ & $\begin{array}{l}150 \\
150 \\
406 \\
150 \\
406 \\
406\end{array}$ & $\begin{array}{r}2.44 \\
7.47 \\
202.08 \\
0.86 \\
1.34 \\
19.07\end{array}$ & $\begin{array}{c}0.004 \\
<0.0001 \\
<0.0001 \\
0.74 \\
0.12 \\
<0.0001\end{array}$ \\
\hline $\begin{array}{l}\text { Relative sheath vertical } \\
\text { colonization }\end{array}$ & $\begin{array}{l}\text { Var } \\
\text { Experiment } \\
\text { DAI } \\
\text { Var } \times \text { experiment } \\
\text { Var } \times \text { DAI } \\
\text { Experiment } \times \text { DAI }\end{array}$ & $\begin{array}{r}14 \\
4 \\
2 \\
56 \\
28 \\
8\end{array}$ & $\begin{array}{l}150 \\
150 \\
406 \\
150 \\
406 \\
406\end{array}$ & $\begin{array}{r}1.49 \\
31.71 \\
246.32 \\
0.81 \\
1.13 \\
23.23\end{array}$ & $\begin{array}{c}0.11 \\
<0.0001 \\
<0.0001 \\
0.81 \\
0.30 \\
<0.0001\end{array}$ \\
\hline Mean lesion length & $\begin{array}{l}\text { Var } \\
\text { Experiment } \\
\text { DAI } \\
\text { Var } \times \text { experiment } \\
\text { Var } \times \text { DAI } \\
\text { Experiment } \times \text { DAI }\end{array}$ & $\begin{array}{r}14 \\
4 \\
2 \\
56 \\
28 \\
8\end{array}$ & $\begin{array}{l}150 \\
150 \\
406 \\
150 \\
406 \\
406\end{array}$ & $\begin{array}{r}1.19 \\
15.20 \\
32.59 \\
1.39 \\
1.46 \\
6.35\end{array}$ & $\begin{array}{l}0.29 \\
<0.0001 \\
<0.0001 \\
0.06 \\
0.06 \\
<0.0001\end{array}$ \\
\hline Maximum lesion length & $\begin{array}{l}\text { Var } \\
\text { Experiment } \\
\text { DAI } \\
\text { Var } \times \text { experiment } \\
\text { Var } \times \text { DAI } \\
\text { Experiment } \times \text { DAI }\end{array}$ & $\begin{array}{r}14 \\
4 \\
2 \\
56 \\
28 \\
8\end{array}$ & $\begin{array}{l}150 \\
150 \\
406 \\
150 \\
406 \\
406\end{array}$ & $\begin{array}{r}1.28 \\
19.30 \\
50.71 \\
1.89 \\
1.24 \\
2.51\end{array}$ & $\begin{array}{l}0.22 \\
<0.0001 \\
<0.0001 \\
0.001 \\
0.19 \\
0.01\end{array}$ \\
\hline Sheath vertical colonization & $\begin{array}{l}\text { Var } \\
\text { Experiment } \\
\text { DAI } \\
\text { Var } \times \text { experiment } \\
\text { Var } \times \text { DAI } \\
\text { Experiment } \times \text { DAI }\end{array}$ & $\begin{array}{r}14 \\
4 \\
2 \\
56 \\
28 \\
8\end{array}$ & $\begin{array}{l}150 \\
150 \\
406 \\
150 \\
406 \\
406\end{array}$ & $\begin{array}{r}1.19 \\
20.28 \\
267.91 \\
1.12 \\
1.28 \\
9.26\end{array}$ & $\begin{array}{l}0.29 \\
<0.0001 \\
<0.0001 \\
0.29 \\
0.16 \\
<0.0001\end{array}$ \\
\hline Distance to furthest lesion & $\begin{array}{l}\text { Var } \\
\text { Experiment } \\
\text { DAI } \\
\text { Var } \times \text { experiment } \\
\text { Var } \times \text { DAI } \\
\text { Experiment } \times \text { DAI }\end{array}$ & $\begin{array}{r}14 \\
4 \\
2 \\
56 \\
28 \\
8\end{array}$ & $\begin{array}{l}150 \\
150 \\
406 \\
150 \\
406 \\
406\end{array}$ & $\begin{array}{r}1.04 \\
16.92 \\
153.97 \\
1.04 \\
1.07 \\
4.38\end{array}$ & $\begin{array}{l}0.42 \\
<0.0001 \\
<0.0001 \\
0.42 \\
0.37 \\
<0.0001\end{array}$ \\
\hline
\end{tabular}

\footnotetext{
${ }^{\text {a }}$ Var $=$ variety $;$ DAI $=$ days after inoculation.
} 

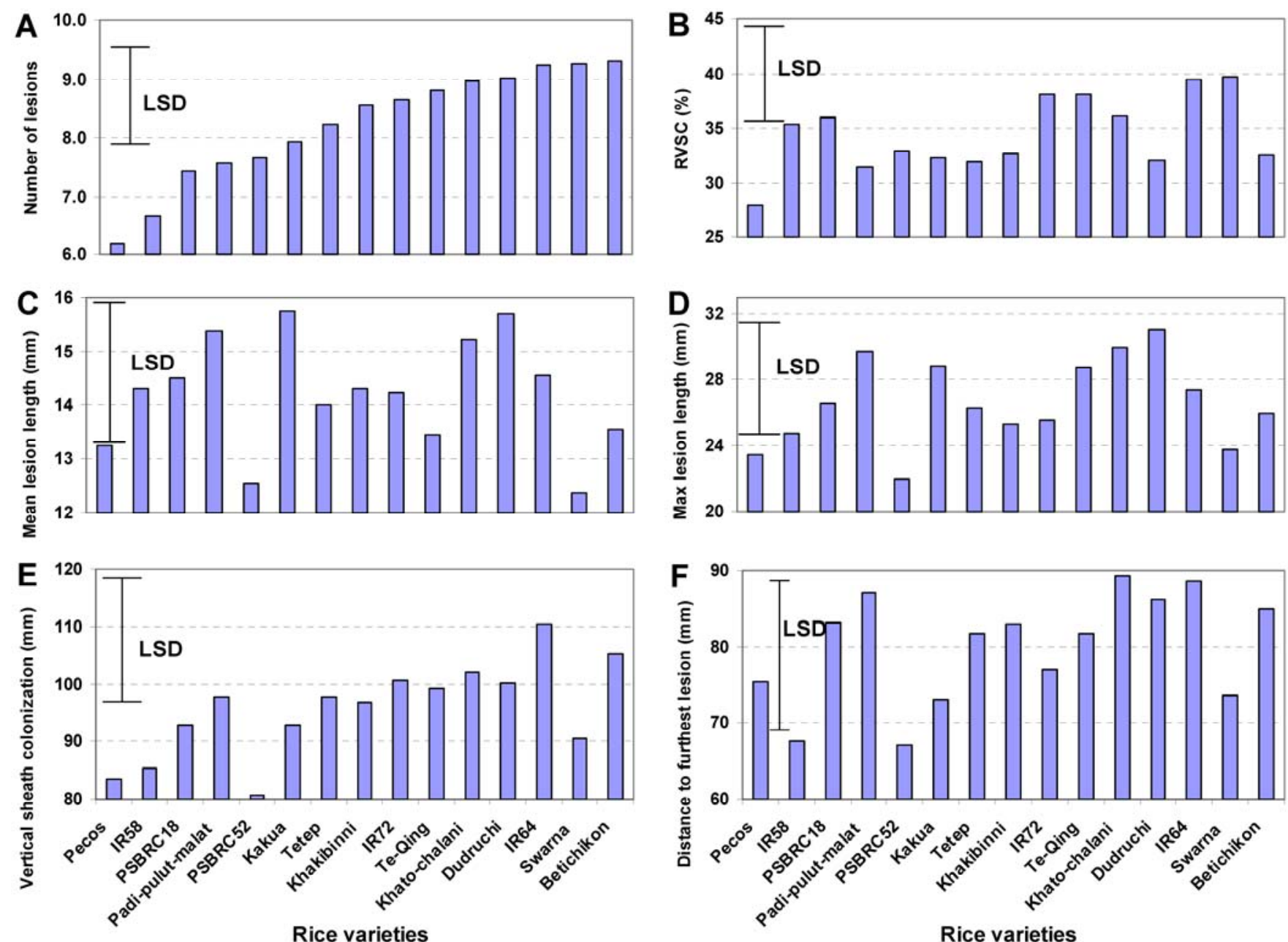

Fig. 3. Rice sheath blight disease variables measured after inoculation on detached tillers on 15 rice varieties. Each bar represents for a given variety the mean of a disease variable over three replications per experiment, three assessments $(5,7$, and 10 days after inoculation) per experiment, and five independent experiments. In each graph, LSD indicates the least significant difference, computed as $2 \times$ MAX (SED), where SED is the standard error of difference of least squares means. A, number of lesions; $\mathbf{B}$, relative vertical sheath colonization (RVSC); C, mean lesion length; $\mathbf{D}$, maximum lesion length; $\mathbf{E}$, vertical sheath colonization (VSC); and $\mathbf{F}$, distance from inoculum to furthest lesion.

Table 4. Mixed model analyses of variance ${ }^{\mathrm{a}}$ on the effects of variety and experiment on rice sheath blight disease variables after inoculation on detached tillers

\begin{tabular}{|c|c|c|c|c|c|c|c|}
\hline \multirow[b]{2}{*}{ Variable analyzed } & \multirow[b]{2}{*}{ Effect $^{\mathrm{c}}$} & \multicolumn{2}{|c|}{5 DAI $^{\mathbf{b}}$} & \multicolumn{2}{|c|}{7 DAI } & \multicolumn{2}{|c|}{10 DAI } \\
\hline & & $F$ value & $P>F$ & $F$ value & $P>F$ & $F$ value & $P>F$ \\
\hline Number of lesions & $\begin{array}{l}\text { Var } \\
\text { Experiment } \\
\text { Var } \times \text { experiment }\end{array}$ & $\begin{array}{r}1.90 \\
36.12 \\
0.68\end{array}$ & $\begin{array}{c}0.03 \\
<0.0001 \\
0.94\end{array}$ & $\begin{array}{l}2.14 \\
2.73 \\
1.00\end{array}$ & $\begin{array}{l}0.01 \\
0.03 \\
0.48\end{array}$ & $\begin{array}{l}2.69 \\
5.83 \\
1.03\end{array}$ & $\begin{array}{l}0.001 \\
0.0001 \\
0.31\end{array}$ \\
\hline $\begin{array}{l}\text { Relative sheath } \\
\text { vertical colonization }\end{array}$ & $\begin{array}{l}\text { Var } \\
\text { Experiment } \\
\text { Var } \times \text { experiment }\end{array}$ & $\begin{array}{r}1.92 \\
57.32 \\
0.98\end{array}$ & $\begin{array}{c}0.03 \\
<0.0001 \\
0.52\end{array}$ & $\begin{array}{r}1.27 \\
18.27 \\
0.71\end{array}$ & $\begin{array}{c}0.23 \\
<0.0001 \\
0.93\end{array}$ & $\begin{array}{r}1.37 \\
25.84 \\
1.11\end{array}$ & $\begin{array}{c}0.17 \\
<0.0001 \\
0.30\end{array}$ \\
\hline Mean lesion length & $\begin{array}{l}\text { Var } \\
\text { Experiment } \\
\text { Var } \times \text { experiment }\end{array}$ & $\begin{array}{r}1.76 \\
25.03 \\
1.77\end{array}$ & $\begin{array}{c}0.05 \\
<0.0001 \\
0.003\end{array}$ & $\begin{array}{l}1.14 \\
5.70 \\
1.01\end{array}$ & $\begin{array}{l}0.33 \\
0.0003 \\
0.47\end{array}$ & $\begin{array}{r}1.19 \\
12.15 \\
1.25\end{array}$ & $\begin{array}{c}0.29 \\
<0.0001 \\
0.15\end{array}$ \\
\hline Maximum lesion length & $\begin{array}{l}\text { Var } \\
\text { Experiment } \\
\text { Var } \times \text { experiment }\end{array}$ & $\begin{array}{r}1.08 \\
22.66 \\
1.80\end{array}$ & $\begin{array}{c}0.38 \\
<0.0001 \\
0.003\end{array}$ & $\begin{array}{l}1.47 \\
8.66 \\
1.48\end{array}$ & $\begin{array}{c}0.13 \\
<0.0001 \\
0.03\end{array}$ & $\begin{array}{l}1.25 \\
8.83 \\
1.38\end{array}$ & $\begin{array}{c}0.24 \\
<0.0001 \\
0.06\end{array}$ \\
\hline Sheath vertical colonization & $\begin{array}{l}\text { Var } \\
\text { Experiment } \\
\text { Var } \times \text { experiment }\end{array}$ & $\begin{array}{r}1.48 \\
54.89 \\
0.96\end{array}$ & $\begin{array}{c}0.13 \\
<0.0001 \\
0.55\end{array}$ & $\begin{array}{r}1.28 \\
13.12 \\
1.21\end{array}$ & $\begin{array}{c}0.23 \\
<0.0001 \\
0.19\end{array}$ & $\begin{array}{l}1.42 \\
9.13 \\
1.47\end{array}$ & $\begin{array}{c}0.15 \\
<0.0001 \\
0.04\end{array}$ \\
\hline Distance to furthest lesion & $\begin{array}{l}\text { Var } \\
\text { Experiment } \\
\text { Var } \times \text { experiment }\end{array}$ & $\begin{array}{r}0.97 \\
37.74 \\
0.96\end{array}$ & $\begin{array}{c}0.49 \\
<0.0001 \\
0.56\end{array}$ & $\begin{array}{l}1.05 \\
9.54 \\
0.95\end{array}$ & $\begin{array}{c}0.41 \\
<0.0001 \\
0.58\end{array}$ & $\begin{array}{l}1.20 \\
8.64 \\
1.38\end{array}$ & $\begin{array}{c}0.28 \\
<0.0001 \\
0.07\end{array}$ \\
\hline
\end{tabular}

a Num df was 14, 4, and 56 for variety, experiment, and experiment $\times$ variety effects, respectively; Den df was 145 for variety, experiment, and experiment $\times$ variety effects.

${ }^{\mathrm{b}}$ DAI = days after inoculation.

c Var = variety. 
tected and may contribute to identifying overall differences in resistance level. Furthermore, the number of lesions and lesion length were not consistently correlated. These variables may thus reflect different mechanisms of partial resistance in rice. VSC and distance to further lesion variables provide an insight on the ability of runner hyphae of the fungus to progress spatially over plant tissues. RVSC provides an indication of (i) the ability of the fungus to progress, and (ii) the relative length of sheath tissue colonized. This second component is associated with disease escape, as taller tillers correspond to larger host size $(2,20,24)$ and thus a reduced ability of the fungus to colonize a large fraction of the host tissue (dilution effect). This latter variable thus combines to some extent the expression of physiological resistance and disease escape.

The representativeness of the results obtained in this study with the LR-1 isolate were assessed by conducting an additional experiment involving a smaller number of rice varieties, chosen for their contrasted characteristics with respect to the detached tiller tests, and five $R$. solani isolates, including LR-1. Detached tiller tests

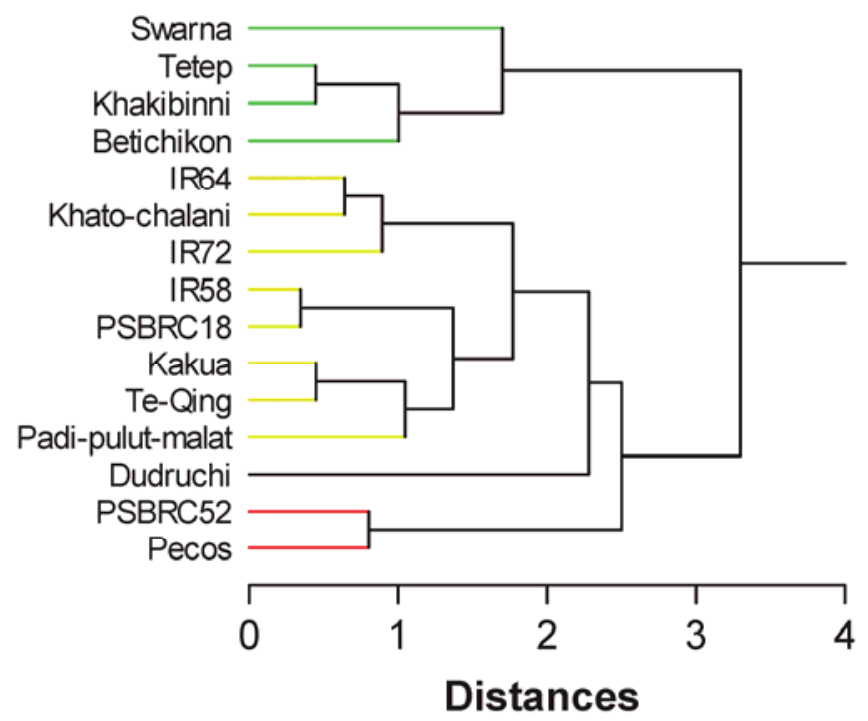

Fig. 4. Clusters of rice varieties according to sheath blight disease variables measured after inoculation on detached tillers. Clusters were generated from hierarchical clustering analysis using the Ward criterion and Mahalanobis distance from 15 rice varieties according to number of lesions, maximum lesion length, and vertical sheath colonization. were conducted with five isolates: LR-1, LG002, NE003, TL034, and PG002. The latter four isolates had been isolated from infected samples taken in rice fields in 2006 in Cavinti (Laguna), Guimba (Nueva Ecija), Concepcion (Tarlac), and Sison (Pangasinan), respectively, which represent different regions in Luzon Island, Philippines. Three independent experiments were conducted. In each test, the five isolates were tested with three varieties (Swarna, IR72, and Pecos) according to a randomized complete block design with five replications (blocks). All 15 combinations (5 isolates $\times 3$ varieties) were randomly assigned within each of the five blocks. The inoculation and incubation methods were performed as described in this article, and disease assessment was performed at 7 DAI with respect to the number of lesions, RVSC, and maximum lesion length. Analyses of variance were conducted to test the effects of cultivar, isolate, experiment, and their interactions. For all three variables (number of lesions, maximum lesion length, and RVSC), only the effect of cultivar was significant $(P<0.0001)$. Specifically, the interaction isolate $\times$ variety was not significant $(P$ $>0.4$ ). The ranking of the three varieties was the same as the one found in the main study reported here for the three variables measured. These results from this additional experiment indicate that isolate LR-1 used for the main study reported here is representative of the pathogen population, at least for Luzon Island.

Cluster analysis represents a formal approach to group varieties according to different components of resistance. Pecos and PSBrc52 were thus grouped together and represent varieties with the lowest levels of disease. IR64, on the other hand, belonged to the group with the highest disease level. As for other plant diseases, improving our knowledge on resistance levels across plant genotypes requires the use of common susceptible and resistant controls, which are used across studies, allowing meta-analyses (49). From our results, IR64 and Pecos could be used in future work as susceptible and resistant controls, respectively, with respect to measurement of components of physiological resistance.

Many varieties were ranked differently, according to the disease variable measured. For example, Swarna had large values for the number of lesions and RVSC, whereas it was associated with low and intermediate values for the other disease variables. Differential response according to components of resistance has been reported for many other diseases, such as barley leaf rust, wheat leaf rust, groundnut rust, and potato late blight $(20,31)$. In the same way, our study indicates that several components of resistance need to be measured in order to provide an overall assessment of the level of resistance to sheath blight.

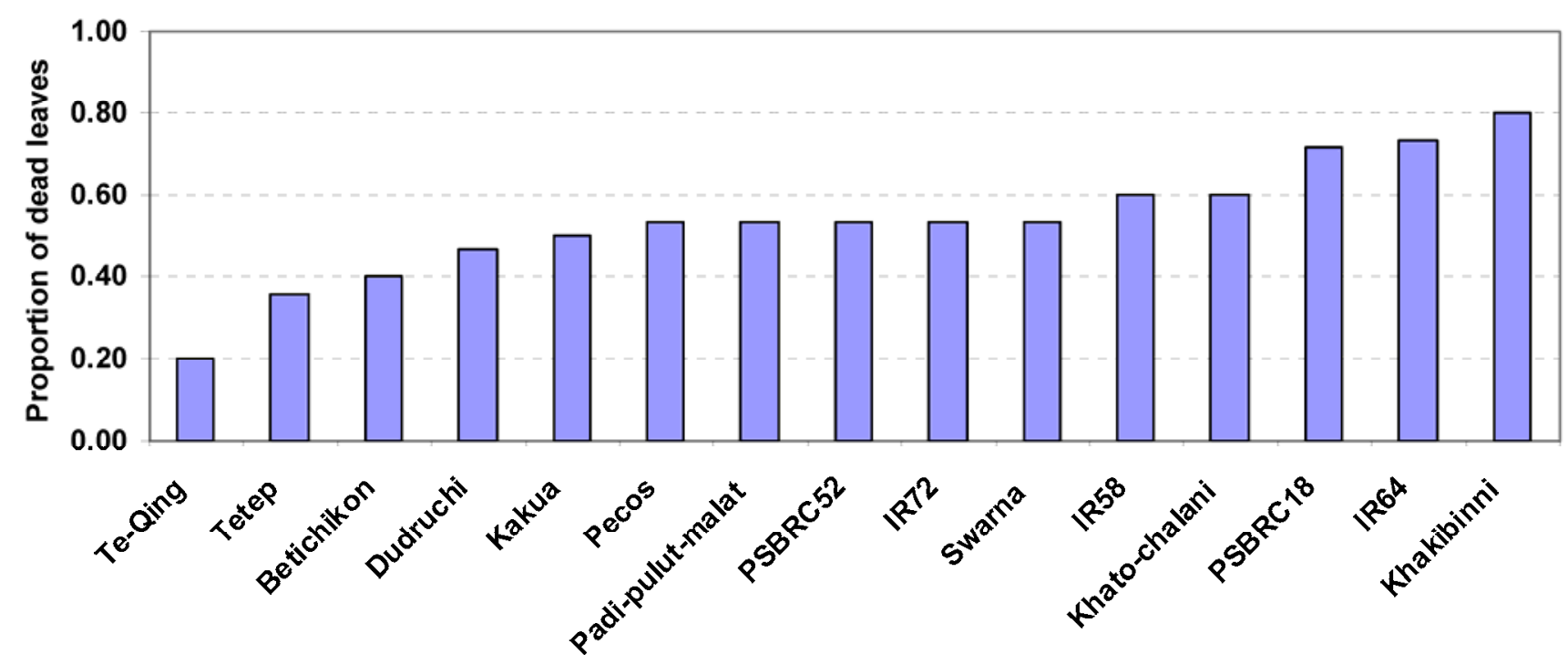

Rice varieties

Fig. 5. Proportion of dead leaves for 15 rice varieties, 7 days after inoculation by Rhizoctonia solani on detached tillers. Each bar represents the fraction computed from the combined 5 experiments. 
The most resistant variety from our study, Pecos, has been earlier reported to have a relatively high level of resistance $(3,38)$. Swarna, which is considered to be a very susceptible variety (42), had high levels of disease intensity with respect to the number of lesions per tiller, and to RVSC. IR58, also considered a very susceptible variety (39), had medium to low disease levels in our experiments. It may be hypothesized that the susceptibility of IR58 to sheath blight may be mainly due to reduced disease escape mechanisms. For example, IR58 is a very short variety, for which the vertical colonization of tissues from the base of a plant upward to its leaf blades will occur faster than for a taller variety. Tetep and Teqing, which are considered to be varieties with high levels of partial resistance, were in general associated to intermediate levels of disease intensity in our study, but had the lowest proportion of dead leaves, which may indicate a larger tolerance to the disease (51).

In a more general way, difference between results obtained here and results obtained from other studies may have several origins: (i) differences in methods and in the types of disease variables measured, that are (ii) associated with differences in resistance mechanisms expressed, and (iii) differences in susceptible controls used. For example, the expression of some defense mechanisms may be higher in the case of the detached tiller tests than in the case of tests performed with detached leaves $(9,25)$, corresponding to plant organs which are surviving in isolation of other tiller and root tissues. Another example is the comparison of tests performed in the field $(15,23)$ with the detached tiller test: the former type of test includes the combined effects of physiological resistance and disease escape, while the latter type focuses on physiological resistance. A third, intermediate example corresponds to the microchamber tests (12), which are performed at the plant scale at a very early stage, and partly incorporates a fair level of disease escape mechanisms (associated with plant height, contact between tillers) compared with the detached tiller test. Comparison is further rendered difficult because variables associated with components of resistance have not been measured in earlier studies on resistance to sheath blight.

The novelty of the methodology described here does not lie within a given technique, but rather in the association of experimental entities (detached tiller), environmental conditions, and disease assessment variables determined on the basis of epidemiological concepts, allowing us to measure partial resistance components of a specific group of resistance mechanisms, i.e., physiological resistance. This methodology may thus allow the detection of sources of resistance that specifically involve defense mechanisms, independently from disease escape mechanisms. Furthermore, this methodology, when combined with a method to measure the effects of both physiological resistance and disease escape, should enable quantitative assessment of the relative role of these two groups of mechanisms of resistance. This should provide further knowledge on plant-pathogen interactions at scales ranging from the tiller to the field, and provide a methodological framework to improve partial resistance to sheath blight in rice varieties.

\section{Acknowledgments}

We thank J. Aguirre, M. Noel, E. Oreiro, I. Mamiit, E. Pizarra, and E. Silab for their technical assistance. We are grateful to I. Oña for providing the four isolates used in the additional study summarized in the Discussion of this article. This work was partly supported by the Bill and Melinda Gates Foundation under the Cereal System Initiative for South Asia.

\section{Literature Cited}

1. Amante, A. D., de la Pena, R., Stich, L. A., Leung, H., and Mew, T. W. 1990. Sheath blight (ShB) resistance in wild rices. Int. Rice Res. Notes 15:5.

2. Arraiano, L. S., Balaam, N., Fenwick, P. M., Chapman, C., Feuerhelm, D., Howell, P., Smith, S. J., Widdowson, J. P., and Brown, J. K. M. 2009. Contributions of disease resistance and escape to the control of Septoria tritici blotch of wheat. Plant Pathol. 58:910-922.

3. Bollich, C. N., Webb, B. D., Marchetti, M. A., and Scott, J. E. 1985. Registration of 'PECOS' Rice. Crop Sci. 25:885-886.

4. Browne, R. A., Bequain, C., and Mascher, F. 2006. Components of partial disease resistance detected using a detached leaf assay in CIMMYT Fusarium head blight resistant wheat germplasm. Eur. J. Plant Pathol. 116:199210 .
5. Channamallikarjuna, V., Sonah, H., Prasad, M., Rao, G. J. N., Chand, S. Upreti, H. C., Singh, N. K., and Sharma, T. R. 2010. Identification of major quantitative trait loci qSBR11-1 for sheath blight resistance in rice. Mol. Breed. 25:155-166.

6. Díaz-Lago, J. E., Stuthman, D. D., and Leonard, K. J. 2003. Evaluation of components of partial resistance to oat crown rust using digital image analysis. Plant Dis. 87:667-674.

7. Fisher, L., and Van Ness, J. W. 1971. Admissible clustering procedures. Biometrika 58:91-104.

8. Green, D. E., II, Burpee, L. L., and Stevenson, K. L. 1999. Components of resistance to Rhizoctonia solani associated with two tall fescue cultivars. Plant Dis. 83:834-838.

9. IRRI. 1987. Annual Report for 1987. IRRI, Los Baños, Philippines.

10. IRRI. 1992. Annual Report for 1992. IRRI, Los Baños, Philippines.

11. IRRI. 1993. Annual Report for 1993. IRRI, Los Baños, Philippines.

12. Jia, Y., Correa-Victoria, F., McClung, A., Zhu, L., Liu, G., Wamishe, Y., Xie, J., Marchetti, M. A., Pinson, S. R. M., Rutger, J. N., and Correll, J. C. 2007. Rapid determination of rice cultivar responses to the sheath blight pathogen Rhizoctonia solani using a micro-chamber screening method. Plant Dis. 91:485-489.

13. Launio, C. C., Redondo, G. O., Beltran, J. C., and Morooka, Y. 2008. Adoption and spatial diversity of later generation modern rice varieties in the Philippines. Agron. J. 100:1380-1389.

14. Leonard, K. J., and Mundt, C. C. 1984. Methods for estimating epidemiological effects of quantitative resistance. Theor. Appl. Genet. 67:219 230 .

15. Li, Z. K., Pinson, S. R. M., Marchetti, M. A., Stansel, J. W., and Park, W. D. 1995. Characterization of quantitative trait loci (QTLs) in cultivated rice contributing to field-resistance to sheath blight (Rhizoctonia solani). Theor. Appl. Genet. 91:382-388.

16. Madden, L. V., Hughes, G., and van den Bosch, F. 2007. The Study of Plant Disease Epidemics. American Phytopathological Society, St. Paul, MN.

17. Mew, T. W., Savary, S., Vera Cruz, C. M., and Leach, J. E. 2004. Looking ahead in rice disease research and management. Crit. Rev. Plant Sci. 23:103-127.

18. Ou, S. H. 1985. Rice Diseases, 2nd ed. Commonwealth Mycological Institute, Surrey, England.

19. Pan, X. B., Rush, M. C., Sha, X. Y., Xie, Q. J., Linscombe, S. D., Stetina, S. R., and Oard, J. H. 1999. Major gene, non-allelic sheath blight resistance from the rice cultivars Jasmine 85 and Teqing. Crop Sci. 39:338-346.

20. Parlevliet, J. E. 1979. Components of resistance that reduce the rate of epidemic development. Annu. Rev. Phytopathol. 17:203-222.

21. Parlevliet, J. E., and van Ommeren, A. 1975. Partial resistance of barley to leaf rust, Puccinia hordei. II. Relationship between field trials, micro plot tests and latent period. Euphytica 24:293-303.

22. Parlevliet, J. E., and Zadoks, J. C. 1977. The integrated concept of disease resistance: A new view including horizontal and vertical resistance in plants. Euphytica 26:5-21.

23. Pinson, S. R. M., Capdevielle, F. M., and Oard, J. H. 2005. Confirming QTLs and finding additional loci conditioning sheath blight resistance in rice using recombinant inbred lines. Crop Sci. 45:503-510.

24. Poland, J. A., Balint-Kurti, P. J., Wisser, R. J., Pratt, R. C., and Nelson, R. J. 2009. Shades of gray: The world of quantitative disease resistance. Trends Plant Sci. 14:21-29.

25. Prasad, B., and Eizenga, G. C. 2008. Rice sheath blight disease resistance identified in Oryza spp. accessions. Plant Dis. 92:1503-1509.

26. Rapilly, F. 1983. Effects of some physical climatic factors on different epidemic sequences. EPPO Bull. 13:63-68.

27. Robinson, R. A. 1976. Plant Pathosystems. Springer Verlag, Berlin.

28. Russell, G. E. 1978. Plant Breeding for Pest and Disease Resistance. Butterworths, London.

29. Sandoval-Islas, J. S., Broers, L. H. M., Mora-Aguilera, G., Parlevliet, J. E., Osada-Kawasoe, S., Vivar, H. E., and Niks, R. 2007. Quantitative resistance and its components in 16 barley cultivars to yellow rust, Puccinia striiformis f. sp. hordei. Euphytica 153:295-308.

30. Sato, H., Ideta, O., Ando, I., Kunihiro, Y., Hirabayashi, H., Iwano, M., Miyasaka, A., Nemoto, H., and Imbe, T. 2004. Mapping QTLs for sheath blight resistance in the rice line WSS2. Breed. Sci. 54:265-271.

31. Savary, S., Bosc, J. P., Noirot, M., and Zadoks, J. C. 1988. Peanut rust in West Africa: A new component in a multiple pathosystem. Plant Dis. 72:1001-1009.

32. Savary, S., Castilla, N. P., Elazegui, F. A., McLaren, C. G., Ynalvez, M. A., and Teng, P. S. 1995. Direct and indirect effects of nitrogen supply and disease source structure on rice sheath blight spread. Phytopathology 85:959-965.

33. Savary, S., Willocquet, L., Elazegui, F. A., Castilla, N., and Teng, P. S. 2000. Rice pest constraints in tropical Asia: Quantification of yield losses due to rice pests in a range of production situations. Plant Dis. 84:357-369.

34. Savary, S., Willocquet, L., Elazegui, F. A., Teng, P. S., Du, P. V., Zhu, D., Tang, Q., Huang, S., Lin, X., Singh, H. M., and Srivastava, R. K. 2000. Rice pest constraints in tropical Asia: Characterization of injury profiles in relation to production situations. Plant Dis. 84:341-356.

35. Savary, S., and Zadoks, J. C. 1989. Analysis of components in the hostparasite interaction of groundnut rust. II. Measurement of intermediate resistance using a micro-plot trial. Oleagineux 44:215-224. 
36. Schabenberger, O., and Pierce, F. J. 2002. Contemporary Statistical Models. Taylor \& Francis, London.

37. Sha, X. Y., and Zhu, L. H. 1990. Resistance of some rice varieties to sheath blight (ShB). Int. Rice Res. Notes 15:7-8.

38. Sharma, A., McClung, A. M., Pinson, S. R. M., Kepiro, J. L., Shank, A. R., Tabien, R. E., and Fjellstrom, R. 2009. Genetic mapping of sheath blight resistance QTLs within tropical japonica rice cultivars. Crop Sci. 49:256-264.

39. Shrestha, C. L., Oña, I., Muthukrishnan, S., and Mew, T. W. 2008. Chitinase levels in rice cultivars correlate with resistance to the sheath blight pathogen Rhizoctonia solani. Eur. J. Plant Pathol. 120:69-77.

40. Singh, A., Rohilla, R., Singh, U. S., Savary, S., Willocquet, L., and Duveiller, E. 2002. An improved inoculation technique for sheath blight of rice caused by Rhizoctonia solani. Can. J. Plant Pathol. 24:65-68.

41. Srinivasachary, Willocquet, L., and Savary, S. 2011. Resistance to rice sheath blight - current status and perspectives. Euphytica 178:1-22.

42. Swain, N. C., Chhotray, A. K., and Mahapatra, S. S. 2005. Pathogenic variability of Rhizoctonia solani causing sheath blight of paddy and its management. J. Plant Prot. Environ. 2:96-99.

43. Tang, Q., Peng, S., Buresh, R. J., Zou, Y., Castilla, N. P., Mew, T. W., and Zhong, X. 2007. Rice varietal difference in sheath blight development and its association with yield loss at different levels of $\mathrm{N}$ fertilization. Field Crops Res. 102:219-227.

44. Tredway, L. P., Stevenson, K. L., and Burpee, L. L. 2003. Components of resistance to Magnaporthe grisea in 'Coyote' and 'Coronado' tall fescue.
Plant Dis. 87:906-912.

45. van Oijen, M. 1992. Evaluation of breeding strategies for resistance and tolerance to late blight in potato by means of simulation. Neth. J. Plant Pathol. 98:3-11.

46. Wasano, K. 1988. The resistance to the rice diseases of bacterial leaf blight (Xanthomonas campestris pv. oryzae) and sheath blight (Rhizoctonia so lani), and some problems in breeding of disease resistance of crops. Pages 103-121 in: Recent Advances in Research on Plant Breeding, Vol. 30. Japanese Society of Breeding, ed. Yokendo, Tokyo.

47. Wilkinson, L., Engelman, L., Corter, J., and Coward, M. 2007. Cluster analysis. Pages I-65 to I-124 in: Statistics I. SYSTAT Software, San Jose, CA.

48. Willocquet, L., Elazegui, F. A., Castilla, N., Fernandez, L., Fischer, K. S., Peng, S., Teng, P. S., Srivastava, R. K., Singh, H. M., Zhu, D., and Savary, 2004. Research priorities for rice disease and pest management in tropical Asia: A simulation analysis of yield losses and management efficiencies. Phytopathology 94:672-682.

49. Yuen, J. E., and Forbes, G. A. 2009. Estimating the level of susceptibility to Phythophtora infestans in potato genotypes. Phytopathology 99:782-786.

50. Zadoks, J. C. 1972. Modern concepts in disease resistance in cereals. Page 89-98 in: The Way Ahead in Plant Breeding. F. A. G. H. Lupton, G. Jenkins, and R Johnson, eds. Eucarpia, Cambridge.

51. Zadoks, J. C., and Schein, R. D. 1979. Epidemiology and Plant Disease Management. Oxford University Press, Oxford, UK. 